\title{
MODEL LINEAR GOAL PROGRAMMING UNTUK MENENTUKAN KAPASITAS TRAFIK BTS PADA SISTEM TELEKOMUNIKASI SELULER GSM
}

\author{
Nafisa As Sofia, Wuryatmo A. Sidik dan Niken Larasati \\ Program Studi Matematika, Fakultas Sains dan Teknik \\ Universitas Jenderal Soedirman \\ nafiesa.shofie@gmail.com
}

\begin{abstract}
A BTS (Base Transceiver Station) is an element that has an important role as a receiver and transmitter of signals. A call request from a mobile phone to another through a BTS will be connected if there is a channel available. In the situation of overload, it is necessary to optimize the use of the bandwidth. This research consider the problem of optimizing the use of BTS's bandwidth by users at four regions of Surabaya. The problem is represented as a mathematical model of the preemptive linear goal programming. The model has two optimization goals with the priority level. The method of sequential goal programming is used. Based on the solution, BTS traffic capacity can accommodate all the traffic demand from cellular phone users if the region A has 131,58 Erlang, region $B$ has 1.425,45 Erlang, region $C$ has 351,4 Erlang, and region $D$ has 619,57 Erlang. The total capacity of traffic does not exceed the total capacity of BTS, because the total traffic capacity is decrease by 81,67 Erlang. The study also shows that a changing in the order of objective goal is not recommended.
\end{abstract}

Keyword: BTS, traffic, preemptive linear goal programming, sequential goal programming.

ABSTRAK. BTS (Base Transceiver Station) merupakan suatu elemen yang berperan penting sebagai pemancar dan penerima sinyal. Suatu permintaan sambungan dari telepon seluler secara otomatis akan terkoneksi ke telepon seluler lainnya jika terdapat kanal untuk akses percakapan. Sebuah BTS mempunyai kapasitas tetap sebesar 2.609,67 Erlang. Jika terjadi kelebihan muatan, maka dibutuhkan proses optimasi penggunaan kapasitas trafik. Pada penelitian ini, dikaji mengenai optimasi kapasitas trafik BTS pada telekomunikasi seluler GSM untuk empat wilayah di Surabaya. Permasalahan tersebut direpresentasikan ke dalam model matematika berupa preemptive linear goal programming. Model yang dibuat mempunyai dua buah tujuan optimasi yang ingin dicapai dengan tingkat prioritas Penyelesaian model menggunakan metode sequential goal programming. Berdasarkan penyelesaian model diketahui bahwa agar kapasitas trafik BTS yang tersedia dapat menampung semua permintaan trafik dari pengguna telepon seluler maka kapasitas trafik yang harus tersedia untuk wilayah A 131,58 Erlang, untuk wilayah B 1.425,45 Erlang, untuk wilayah C 351,4 Erlang, untuk wilayah D 619,57 Erlang. Total kapasitas trafik tidak melebihi total kapasitas yang dimiliki BTS, karena totalnya berkurang sebesar 81,67 Erlang Penelitian ini menujukkan bahwa perubahan urutan pada tujuan optimasi tidak dianjurkan.

Kata kunci: BTS, trafik, preemptive linear goal programming, sequential goal programming. 


\section{PENDAHULUAN}

Perkembangan dunia telekomunikasi di Indonesia saat ini sangat pesat, terutama pada komunikasi seluler. Hal ini ditandai dengan semakin banyak teknologi tanpa kabel yang digunakan oleh masyarakat. Salah satu teknologi tanpa kabel yang digunakan oleh masyarakat adalah telepon seluler GSM. GSM adalah salah satu teknologi digital standar yang berasal dari wilayah Eropa di mana teknologi tersebut bekerja pada jaringan berfrekuensi 900 Mhz sampai dengan 1900 Mhz (Rizki, 2012). Dalam jaringan GSM terdapat banyak elemen (network element), salah satunya adalah BTS (Base Transceiver Station) yang merupakan suatu elemen dalam jaringan seluler (Cell Network) yang berperan penting sebagai pemancar dan penerima sinyal dari dan menuju telepon seluler. (Martin, 2011).

Menurut data Asosiasi Telepon Seluler Indonesia (ATSI), pengguna layanan seluler di Indonesia semakin bertambah tiap tahunnya (Iskandar, 2013). Meningkatnya pengguna telepon seluler menjadi penyebab meningkatnya permintaan sambungan dari pengguna telepon seluler yang juga akan menyebabkan peningkatan permintaan trafik. Ketika permintaan trafik terus bertambah tanpa adanya evaluasi terhadap kapasitas trafik yang tersedia pada BTS, kemungkinan yang terjadi adalah kelebihan muatan. Artinya, jumlah muatan yang tidak seimbang dengan permintaan akan mengakibatkan provider memberikan kualitas layanan sesuai trafik yang tersedia. Jika hal ini terus menerus terjadi, pengguna telepon seluler bisa saja beralih ke layanan yang ditawarkan oleh provider lain. Tentu hal seperti ini tidak diinginkan oleh perusahaan telekomunikasi seluler, sehingga perusahaan perlu melakukan optimasi kapasitas trafik BTS agar dapat menanggulangi terjadinya kelebihan muatan. Untuk menyelesaikan permasalahan perusahaan, jarang sekali kita temui perusahaan dengan satu tujuan, karena pada umumnya tujuan didirikan perusahaan untuk mencapai beberapa tujuan. Agar dapat tercapainya beberapa tujuan dengan tingkat prioritas yang berbeda dalam waktu yang bersamaan, dibutuhkan sebuah teknik yang mampu menyelesaikannya. Secara matematis, terdapat suatu teknik yang bisa digunakan untuk menganalisa permasalahan yang memiliki beberapa tujuan dengan tingkat prioritas dalam waktu yang bersamaan, 
yaitu teknik preemptive linear goal programming (Ignizio dan Romero, 2009: 489). Metode sequential goal programming adalah salah satu metode yang digunakan untuk menyelesaikan teknik preemptive linear goal programming (Lieberman dan Hillier, 2001: 336).

Oleh karena itu, penulis tertarik untuk memformulasikan masalah kapasitas trafik BTS pada empat wilayah di Surabaya ke dalam model matematis berupa preemptive linear goal programming dengan tujuan memenuhi permintaan trafik dari pengguna telepon seluler, terutama agar dapat meminimalisir terjadinya overload. Model yang disusun dalam penelitian ini memiliki dua tujuan optimasi yang ingin dicapai yaitu kapasitas trafik BTS yang dapat menampung permintaan trafik pengguna dan total kapasitas trafik yang tidak melebihi kapasitas masingmasing BTS. Selanjutnya, akan dikaji mengenai perubahan urutan pada tujuan optimasi, untuk melihat bagaimana pengaruhnya terhadap tujuan optimasi yang ingin dicapai.

Berdasarkan uraian pada latar belakang, ada tiga permasalahan yang dapat dirumuskan yaitu, bagaimana menentukan kapasitas trafik yang bisa menampung semua permintaan trafik dari pengguna telepon seluler dan kapasitas total trafik BTS yang tidak melebihi total kapasitas yang dimiliki masing-masing BTS, bagaimana pengaruh yang terjadi ketika dilakukan perubahan urutan pada tujuan optimasi dan apa yang harus dilakukan agar BTS tidak mengalami overload. Tujuan dari penelitian ini adalah menentukan jumlah kapasitas trafik yang bisa menampung semua permintaan trafik dari pengguna telepon seluler dan menentukan kapasitas total trafik BTS yang tidak melebihi total kapasitas yang dimiliki masing-masing BTS, mengetahui pengaruh yang terjadi ketika dilakukan perubahan urutan pada tujuan optimasi, dan mengetahui tindakan yang harus dilakukan agar BTS tidak mengalami overload. Adapun manfaat yang dapat diperoleh dari penelitian ini adalah menambah pengetahuan dan wawasan mengenai penerapan matematika

dalam bidang telekomunikasi khususnya pada model linear goal programming untuk menentukan kapasitas trafik BTS dan Memberikan masukan keputusan kepada operator jasa telekomunikasi untuk menentukan kapasitas trafik BTS yang 
optimal pada empat wilayah di Surabaya dan mengoptimalkan total kapasitas trafiknya.

Tabel 1. Data jumlah sektor, kapasitas trafik dan jumlah permintaan trafik BTS pada empat kecamatan di Surabaya

\begin{tabular}{|c|c|c|c|c|}
\hline No. & Wilayah & $\begin{array}{c}\text { Jumlah } \\
\text { sektor } \\
\text { (buah) }\end{array}$ & $\begin{array}{c}\text { Kapasitas } \\
\text { Trafik } \\
\text { (Erlang) }\end{array}$ & $\begin{array}{c}\text { Kapasitas } \\
\text { Trafik dengan } \\
\text { probabilitas } \\
\text { blocking } \\
\text { (Erlang) }\end{array}$ \\
\hline 1 & $\begin{array}{c}\text { Bagian A } \\
\text { (kecamatan Asemrowo) }\end{array}$ & 6 & 180 & 131,58 \\
\hline 2 & $\begin{array}{c}\text { Bagian B } \\
\text { (kecamatan Gubeng) }\end{array}$ & 65 & 1.950 & $1.425,45$ \\
\hline 3 & $\begin{array}{c}\text { Bagian C } \\
\text { (kecamatan Kenjeran) }\end{array}$ & 16 & 480 & 350,88 \\
\hline 4 & $\begin{array}{c}\text { Bagian D } \\
\text { (kecamatan }\end{array}$ & 32 & 960 & 701,76 \\
\hline \multicolumn{2}{|l|}{ Prembangan) }
\end{tabular}

Sumber: Hakim, M. F., Anggraeni, W., dan Pribadi, A., 2012. Optimasi Perencanaan Jumlah BTS dan Kapasitas Trafik BTS Menggunakan Pendekatan Goal Programming pada Sistem Telekomunikasi Seluler GSM Jurnal Teknik ITS, pp: 6.

\section{METODE PENELITIAN}

Pada penelitian ini metode yang digunakan dalam penelitian ini adalah studi pustaka. Adapun langkah-langkah yang dilakukan terdiri dari menentukan variabel keputusan, menentukan fungsi tujuan dan prioritas pada fungsi tujuan, menentukan pembatas, menentukan model matematika berupa preemptive linear goal programming yang digunakan untuk menentukan kapasitas trafik BTS, menyelesaikan model preemptive linear goal programming dengan menggunakan metode sequential goal programming, melakukan perubahan urutan pada tujuan optimasi. Data yang digunakan berupa data sekunder yang diambil dari jurnal. 


\section{HASIL DAN PEMBAHASAN}

\subsection{Model Preemptive Linear Goal Programming untuk Menentukan}

\section{Kapasitas Trafik Masing-masing BTS di Setiap Bagian Wilayah}

Model preemptive linear goal programming yang digunakan untuk menentukan kapasitas trafik masing-masing BTS untuk empat wilayah di Surabaya memuat dua tujuan, dengan tujuan prioritas kesatu adalah kapasitas trafik yang tersedia dapat menampung semua permintaan trafik dari pengguna telepon seluler dan tujuan kedua adalah kapasitas total trafik BTS tidak melebihi total kapasitas yang dimiliki masing-masing BTS. Selanjutnya, akan dilakukan perubahan urutan pada tujuan optimasi, sehingga tujuan prioritas kesatu adalah kapasitas total trafik BTS tidak melebihi total kapasitas yang dimiliki masingmasing BTS dan tujuan kedua adalah kapasitas trafik yang tersedia dapat menampung semua permintaan trafik dari pengguna telepon seluler. Penentuan model preemptive linear goal programming untuk menentukan kapasitas trafik masing-masing BTS untuk empat wilayah di Surabaya terbagi atas penentuan fungsi tujuan, pembatas, dan prioritas. Berikut adalah penjelasan untuk masingmasing bagian.

\subsubsection{Penentuan Variabel keputusan}

Variabel keputusan pada masalah infrastruktur jaringan GSM menggambarkan keadaan infrastruktur jaringan seluler berupa kapasitas trafik masing-masing BTS pada empat wilayah di Surabaya. Dengan demikian, variabel keputusan didefinisikan sebagai berikut:

$x_{1}=$ kapasitas trafik pada wilayah bagian A (kecamatan Asemrowo).

$x_{2}=$ kapasitas trafik pada wilayah bagian B (kecamatan Gubeng).

$x_{3}=$ kapasitas trafik pada wilayah bagian C (kecamatan Kenjeran).

$x_{4}=$ kapasitas trafik pada wilayah bagian D (kecamatan Krembangan). 


\subsubsection{Penentuan Fungsi Tujuan dan Prioritasnya}

Tujuan prioritas kesatu yang ingin dicapai pertama kali adalah meminimumkan penyimpangan yang mengakibatkan kapasitas trafik tidak mampu menampung permintaan sebesar 2.528 Erlang. Secara matematis dapat ditulis menjadi

$$
\text { Minimumkan } Z=P_{1} d_{1}^{-}
$$

Tujuan prioritas kedua yang ingin dicapai selanjutnya adalah meminimumkan penyimpangan yang mengakibatkan total kapasitas trafik BTS lebih besar dari 2.609,67 Erlang. Secara matematis dapat ditulis menjadi

$$
\text { Minimumkan } Z=P_{2} d_{2}^{+}
$$

\subsubsection{Penentuan Pembatas}

1. Pembatas kapasitas trafik yang harus disediakan

Pembatas pertama ini berhubungan erat dengan tujuan prioritas kesatu karena pembatas ini merupakan implementasi dari tujuan pertama yang akan dicapai, sehingga pembatas yang digunakan adalah

$$
x_{1}+x_{2}+x_{3}+x_{4}-d_{1}^{+}+d_{1}^{-}=2.528
$$

2. Pembatas kapasitas trafik maksimal yang dimiliki seluruh BTS

Pembatas kedua ini berhubungan erat dengan tujuan prioritas kedua karena pembatas ini merupakan implementasi dari tujuan kedua yang akan dicapai, sehingga pembatas yang digunakan adalah

$$
x_{1}+x_{2}+x_{3}+x_{4}-d_{2}^{+}+d_{2}^{-}=2.609,67
$$

3. Pembatas kapasitas trafik dengan probabilitas blocking setiap BTS masingmasing bagian wilayah

$$
\begin{aligned}
& x_{1} \leq 131,58 \\
& x_{2} \leq 1.425,45 \\
& x_{3} \leq 350,88 \\
& x_{4} \leq 701,76 .
\end{aligned}
$$


4. Pembatas kapasitas minimal penggunaan BTS per pengguna setiap wilayah

$$
\begin{aligned}
& x_{1} \geq 0,52 \\
& x_{2} \geq 0,52 \\
& x_{3} \geq 0,52 \\
& x_{4} \geq 0,52 .
\end{aligned}
$$

\subsection{Penyelesaian Model dengan Menggunakan Metode Sequential Goal}

\section{Programming untuk Masalah Penentuan Jumlah Kapasitas Trafik}

Bentuk umum model preemptive linear goal programming untuk masalah penentuan kapasitas trafik pada empat wilayah di Surabaya yaitu sebagai berikut.

$$
\text { Minimumkan } Z=P_{1} d_{1}^{-}, P_{2} d_{2}^{+}
$$

dengan pembatas:

$$
\begin{aligned}
& x_{1}+x_{2}+x_{3}+x_{4}+d_{1}^{-}-d_{1}^{+} \\
& =2.528,00 \\
& x_{1}+x_{2}+x_{3}+x_{4}+d_{2}^{-} \quad-d_{2}^{+} \quad=2.609,67 \\
& x_{1} \\
& +s_{1} \\
& =131,58 \\
& x_{2} \\
& +s_{2} \\
& =1.425,45 \\
& x_{3} \\
& +s_{3} \\
& =350,88 \\
& x_{4} \quad+s_{4} \\
& =701,76 \\
& x_{1} \\
& +s_{5} \quad-q_{1} \quad=0,52 \\
& x_{2} \\
& +s_{6} \quad-q_{2} \quad=0,52 \\
& x_{3} \\
& +s_{7} \quad-q_{3} \quad=\quad 0,52 \\
& \begin{array}{llll}
x_{4} & +s_{8} & -q_{4} & =
\end{array} \quad 0,52 \\
& x_{1}, x_{2}, x_{3}, x_{4}, d_{1}^{-}, d_{1}^{+}, d_{2}^{-}, d_{2}^{+}, s_{1}, s_{2}, s_{3}, s_{4}, s_{5}, s_{6}, s_{7}, s_{8}, q_{1}, q_{2}, q_{3}, q_{4} \geq 0 .
\end{aligned}
$$

Langkah selanjutnya adalah menyelesaikan model yang telah dibentuk, dengan menggunakan metode sequential goal programming. Metode sequential goal programming merupakan metode penyelesaian masalah goal programming yang memuat dua fungsi tujuan atau lebih dengan cara penyelesaian secara bertahap. Artinya, penyelesaian dilakukan untuk menyelesaikan model dengan tujuan 
prioritas kesatu terlebih dahulu, setelah diperoleh hasil optimal untuk tujuan dengan priorits kesatu akan dilanjutkan penyelesaian untuk tujuan dengan prioritas berikutnya.

Dengan menggunakan metode sequential goal programming, diperoleh kapasitas trafik pada wilayah bagian A $\left(x_{1}\right)$ 131,58 Erlang, kapasitas trafik pada wilayah bagian B $\left(x_{2}\right)$ 1.425,45 Erlang, kapasitas trafik pada wilayah bagian C $\left(x_{3}\right)$ 351,4 Erlang, kapasitas trafik pada wilayah bagian D $\left(x_{4}\right) 619,57$ Erlang. Dengan nilai $d_{1}^{-}=0$ dan $d_{1}^{+}=0$, maka dapat disimpulkan bahwa tujuan dengan prioritas kesatu tercapai dengan baik tanpa ada nilai penyimpangan dengan kapasitas trafik yang tersedia untuk seluruh BTS sebesar 2.528 Erlang. Begitupula untuk tujuan kedua, karena kapasitas total trafik nya tidak melebihi total kapasitas seharusnya. Akan tetapi, kapasitas total trafiknya menjadi berkurang sebanyak 81,67 Erlang, karena memiliki nilai simpangan bawah yaitu $d_{2}^{-}=81,67$.

\subsection{Pengaruh Perubahan Urutan pada Tujuan Optimasi}

Perubahan urutan yang dimaksud pada sub bab ini adalah merubah urutan pada fungsi tujuan dan pembatas yang berkaitan dengan tujuan yang ingin dicapai. Perubahan berkenaan dengan urutan letak. Oleh karena itu, pada sub bab ini akan dilakukan perubahan urutan letak pada tujuan yaitu tujuan dengan prioritas kesatu dan pembatas berkaitan dengan tujuan prioritas kesatu yang awalnya terletak di urutan pertama dirubah menjadi tujuan dan pembatas berkaitan dengan tujuan prioritas kesatu yang terletak di urutan kedua dan sebaliknya. Jadi, tujuan yang akan dicapai terlebih dahulu adalah menentukan kapasitas total trafik BTS agar tidak melebihi total kapasitas yang dimiliki masing-masing BTS. Kemudian, menyelesaikan tujuan selanjutnya yang terletak pada urutan kedua yaitu menentukan kapasitas trafik yang bisa menampung semua permintaan trafik dari pengguna telepon seluler.

Bentuk umum model preemptive linear goal programming setelah dilakukan perubahan urutan untuk masalah penentuan kapasitas trafik pada empat wilayah di Surabaya yaitu sebagai berikut. 


$$
\text { Minimumkan } Z=P_{2} d_{2}^{+}, P_{1} d_{1}^{-}
$$

dengan pembatas:

$$
\begin{aligned}
& \begin{array}{lll}
x_{1}+x_{2}+x_{3}+x_{4}+d_{2}^{-} & -d_{2}^{+} & =2.609,67
\end{array} \\
& \begin{array}{llll}
x_{1}+x_{2}+x_{3}+x_{4} & +d_{1}^{-} & -d_{1}^{+} & =2.528,00
\end{array} \\
& \begin{array}{lll}
x_{1} & +s_{1} & =131,58
\end{array} \\
& \begin{array}{lll}
x_{2} & +s_{2} & =1.425,45
\end{array} \\
& \begin{array}{lll}
x_{3} & +s_{3} & =350,88
\end{array} \\
& x_{4} \quad+s_{4} \quad=701,76 \\
& \begin{array}{llll}
x_{1} & +s_{5} & -q_{1} & =
\end{array} \\
& \begin{array}{llll}
x_{2} & +s_{6} & -q_{2} & =
\end{array} \\
& \begin{array}{llll}
x_{3} & +s_{7} & -q_{3} & =
\end{array} \\
& \begin{array}{llll}
x_{4} & +s_{8} & -q_{4}= & 0,52
\end{array} \\
& x_{1}, x_{2}, x_{3}, x_{4}, d_{1}^{-}, d_{1}^{+}, d_{2}^{-}, d_{2}^{+}, s_{1}, s_{2}, s_{3}, s_{4}, s_{5}, s_{6}, s_{7}, s_{8}, q_{1}, q_{2}, q_{3}, q_{4} \geq 0 \text {. }
\end{aligned}
$$

Dengan menggunakan metode sequential goal programming, model diatas tidak dapat diselesaikan dengan baik karena terdapat tahapan pada metode sequential yang tidak bisa dilakukan. Jadi, proses penukaran kepentingan prioritas dalam tujuan tidak memberi pengaruh. Artinya, pada permasalahan ini, hanya terdapat satu urutan dalam memprioritaskan fungsi tujuan sehingga kedua tujuan optimasi tercapai.

\section{KESIMPULAN DAN SARAN}

Berdasarkan hasil dan pembahasan permasalahan optimasi kapasitas trafik BTS untuk empat wilayah di Surabaya, diperoleh kesimpulan sebagai berikut:

1. Kapasitas trafik yang disediakan agar bisa menampung semua permintaan trafik dari pengguna telepon seluler adalah sebagai berikut:
a. Bagian A (kecamatan Asemrowo) sebesar 131,58 Erlang
b. Bagian B (kecamatan Gubeng) sebesar 1.425,45 Erlang
c. Bagian C (kecamatan Kenjeran) sebesar 351,4 Erlang
d. Bagian D (kecamatan Krembangan) sebesar 619,57 Erlang 
Dengan kapasitas total trafik BTS adalah sebesar 2.528 Erlang. Hal ini berarti, tujuan kesatu dari permasalahan ini tercapai dengan baik. Begitupula untuk tujuan kedua, karena kapasitas total trafik nya tidak melebihi total kapasitas seharusnya. Akan tetapi, kapasitas total trafiknya menjadi berkurang sebanyak 81,67 Erlang.

2. Pada penelitian ini, agar BTS tidak mengalami overload tujuan kesatu yang harus dicapai adalah memenuhi kapasitas trafik yang tersedia agar dapat menampung permintaan trafik. Selanjutnya, menyelesaikan tujuan kedua yaitu agar kapasitas total trafik BTS tidak melebihi total dari kapasitas masing-masing BTS.

Penelitian ini membahas mengenai model preemptive linear goal programming masalah penentuan jumlah kapasitas trafik BTS agar dapat menampung permintaan trafik dari pengguna layanan seluler berupa permintaan sambungan panggilan dari suatu operator tertentu dengan menggunakan metode penyelesaian berupa sequential goal programming. Penelitian lebih lanjut, dapat dilakukan mengenai jumlah BTS dan dapat menyelesaikan masalah goal programming dengan menggunakan metode lain seperti streamlined goal programming

\section{DAFTAR PUSTAKA}

Ignizio, J. P., dan Romero, C., 2009. Goal Progamming. Elsevier Science, USA. Iskandar, 2013. Tren Telepon Seluler Diawali dengan Teknologi GSM. [online] diunduh dari: http://tekno.liputan6.com/read/751928/ [diakses pada 8 Maret 2014].

Lieberman, G. J., dan Hillier, F. S., 2001. Introduction to Operation Research Seven Edition. MacGraw Hill, New York.

Martin, 2011. BTS berfungsi Penerima dan Pengirim Sinyal Komunikasi. [online] diunduh dari: http://lampung.tribunnews.com/ [diakses pada 16 Mei 2014].

Rizki, A., 2012. Mengenal Jaringan GSM. [online] diunduh dari: http://www.adityarizki.net [diakses pada 12 April 2014]. 